\title{
Agricultural performance and genetic parameters for yield-related traits of sugar- and energy cane families derived from planned crosses
}

A.R. Fernandes Júnior, A.A.C. de Azeredo, R.A. de Oliveira, J.C. Bespalhok Filho, O.T. Ido, E. Daros and B.P. Brasileiro

Departamento de Fitotecnia e Fitossanitarismo, Universidade Federal do Paraná, Curitiba, PR, Brasil

Corresponding author: A.A.C. de Azeredo

E-mail: afonso@agronomo.eng.br

Genet. Mol. Res. 16 (3): gmr16039773

Received July 10, 2017

Accepted August 28, 2017

Published September 27, 2017

DOI http://dx.doi.org/10.4238/gmr16039773

Copyright $(2017$ The Authors. This is an open-access article distributed under the terms of the Creative Commons Attribution ShareAlike (CC BY-SA) 4.0 License.

\begin{abstract}
The forecast of a growing energy demand in the coming years has aroused particular interest in biomass for energy cogeneration, to diversify the energy matrix by using clean and renewable sources. To meet the new demands of the sugarcane industry, this study evaluated the agronomic performance and estimated genetic parameters for yield traits in sugar- and energy cane families derived from planned crosses. The cane families were assessed in the northwest of the State of Paraná, county of Paranavaí, in a randomized complete block design, with three replications. The evaluations were carried out 12 months after the first cut, in the ratoon cane cycle, in December 2014, under very unfavorable conditions for the crop, due to the low fertility and waterholding capacity of the soil. Besides, the crop was evaluated at the end of the harvest, when the agricultural and industrial quality of the crop is reduced. The following traits were evaluated at the plot level: soluble
\end{abstract}


solids content, apparent sucrose content (PC), fiber content, tons of cane per hectare, tons of sucrose per hectare (TSH), and tons of fiber per hectare (TFH). High genetic variability was observed for all evaluated traits, with accuracy estimates from 0.69 (TSH) to 0.92 (PC), and high heritability (up to 0.84 ), indicating the possibility of genetic progress. The sugarcane families derived from crosses of Saccharum spontaneum and Saccharum robustum species with sugarcane hybrids had the highest fiber contents. Highest sugar contents were found in sugarcane families resulting from crosses of sugarcane clones and conventional cultivars. The TSH means were highest in the families F160 x MEX68200 and RB855156 x RB987935. The highest genotypic mean for TFH was observed in the special polycross involving cultivar RB036066 with $S$. spontaneum accessions as pollen donors.

Key words: Saccharum spp; Biomass; Heritability; Breeding

\section{INTRODUCTION}

Sugarcane (Saccharum spp) is one of the most efficient crops regarding solar-tochemical energy conversion, for being a $\mathrm{C} 4$ species with high biomass production (Tew and Cobill, 2008). In Brazil, it is one of the main, economically most competitive options for biomass production, mainly because of the well-established and equipped processing industry, the high standards of cultivation and processing techniques, as well as the considerable number of sugar mill plants distributed throughout the country (Matsuoka et al., 2014).

Biomass has been identified as one of the main alternatives for the diversification of the energy matrix, contributing to the reduction of the use of fossil fuels. This energy source has attracted interest due to the expected strong growth in energy demand in the coming years (Vichi and Mansor, 2009).

According to Dal-Bianco et al. (2012), breeding work with sugarcane has obtained increases in sucrose yield over centuries, and the current commercial cultivars were selected for a higher sucrose content and lower fiber production. With the feasibility of using straw and the prospect of using the entire cane biomass in the production of cellulosic ethanol and other products, new lines of sugarcane research have arisen in Brazil and other countries, mainly focused on increasing the fiber content and biomass production of future cultivars (Matsuoka et al., 2014; Silveira et al., 2016).

The species Saccharum spontaneum and Saccharum robustum have higher fiber contents than the current cultivars (Saccharum spp). To increase the fiber content of future cultivars, some researchers propose the exploitation of crosses between accessions of these species with sugarcane cultivars with high yields, aiming at the selection of clones with high biomass production and higher fiber contents, called energy cane (Ming et al., 2006; Wang et al., 2008; Silveira et al., 2015a,b, 2016; Ramos et al., 2017; de Azeredo et al., 2017).

According to Tew and Cobill (2008), the currently grown sugarcane cultivars contain approximately $12 \%$ fiber, $13 \%$ sugar, and $75 \%$ water. By breeding, energy cane cultivars can be developed containing $30 \%$ fiber, $5 \%$ sugar, and $65 \%$ water. The development of genotypes with this composition is a relatively long process. It should also be remembered that the industry of the sector is not yet ready to process biomass with fiber contents above $20 \%$, but

Genetics and Molecular Research 16 (3): gmr16039773 
the development of cultivars with fiber contents of around $17 \%$ that maintain a sucrose content of approximately $13 \%$ would meet the current needs of the sugar-energy sector. This type of cultivar would increase the electric power production capacity by increasing fiber percentage and consequently bagasse quality, without causing losses in sugar production (Matsuoka et al., 2014).

For many researchers, after hybridization, the families must be tested, performing individual selection in families with high genotypic values, increasing the probability of finding superior clones in the progenies (Simmonds, 1996; Kimbeng and Cox, 2003; Barbosa et al., 2005; Resende and Barbosa, 2006). Several breeding programs have routinely applied family selection and demonstrated the advantages of developing transgressive clones, promoting genetic progress and contributing to the establishment of new cultivars (Stringer et al., 2011; Oliveira et al., 2011; Barbosa et al., 2012; Zeni Neto et al., 2013; Brasileiro et al., 2016).

In view of the need to obtain cultivars that meet the current and future demands of the sugarcane industry, parents previously not used in sugarcane hybridization programs, such as accessions of $S$. spontaneum and $S$. robustum, started to arouse the interest of the breeders, mainly due to the need for a new biotype for the crop, i.e., the search for energy cane cultivars, created a new demand and new parents were incorporated into the hybridization programs. Accordingly, given the need to know the potential of these parents, the objective of this study was to evaluate the agricultural performance and to estimate genetic parameters for yieldrelated traits of sugar- and energy cane families derived from planned crosses.

\section{MATERIAL AND METHODS}

In this study, 30 families of crosses planned according to their genealogy were evaluated, 5 of them for sugarcane (SC), with elite sugarcane parents (clones and cultivars); 12 intermediate (INT) families of the second and third generations of S. spontaneum, 13 energy cane (EC) accessions and descendants of S. spontaneum and S. robustum (Table 1).

The crosses were carried out in 2012 at the Experimental Station Serra do Ouro $\left(9^{\circ} 13^{\prime} \mathrm{S}\right.$, $35^{\circ} 50^{\prime} \mathrm{W}, 450 \mathrm{~m}$ asl), of the Federal University of Alagoas, in the county of Murici, Alagoas.

Table 1. Genealogy of the parents used to obtain the 30 families evaluated in Paranavaí - PR, Brazil.

\begin{tabular}{l|c|c|c|c|c}
\hline Mother & Father & Parents & Mother & Father & Parents \\
\hline B35187 & Co617 & MEX68-200 & RB72454 & TUC71-7 & RB855156 \\
\hline Co421 & Co313 & CoS245 & RB72454 & $?$ & RB867515 \\
\hline Co951 & Co419 & Co62175 & RB855156 & RB815690 & RB966928 \\
\hline CP71-321 & US72-19 & TUC77-42 & SP71-1088 & H57-5028 & SP80-3280 \\
\hline L65-69 & SES297A & US74-103 & Co740 & SP70-1143 & IAC87-3396 \\
\hline NCo310 & PT43-52 & F150 & Co62175 & RB72454 & RB01640 \\
\hline NCo310 & F141 & F160 & SP70-1143 & SP77-5181 & RB036066 \\
\hline NG28288 & S. spontaneum & B70710 & RB745464 & RB92524 & RB04813 \\
\hline POJ2364 & EK28 & POJ2878 & NA56-79 & SP70-1143 & RB83102 \\
\hline POJ2878 & Co285 & Co421 & RB75126 & RB72199 & RB92579 \\
\hline POJ2878 & Co285 & Co617 & RB72454 & $?$ & RB93509 \\
\hline S. robustum & $?$ & IM76-228 & CP70-1547 & SP71-1279 & SP81-3250 \\
\hline S. robustum & $?$ & $28 N G 289$ & RB835867 & $?$ & RB01623 \\
\hline S. robustum & $?$ & IM76-229 & RB72454 & RB83102 & RB987935 \\
\hline S. spontaneum & US60-313 & US85-1008 & RB855536 & NA73-1454 & RB965518 \\
\hline S. spontaneum & $?$ & IN84-58 & SP80-3280 & $?$ & RB996961 \\
\hline S. spontaneum & $?$ & IN84-88 & CP48-124 & R & RB813804 \\
\hline Str. Mauritius & S. spontaneum & Co285 & RB931013 & RB72910 & RB04823 \\
\hline & & & & &
\end{tabular}

Genetics and Molecular Research 16 (3): gmr16039773 
After processing, the caryopses originated from the crosses were sent to an experimental station of the Federal University of Paraná, in Paranavaí, State of Paraná $\left(23^{\circ} 05^{\prime} \mathrm{S} ; 52^{\circ} 27^{\prime} \mathrm{W}\right.$; $503 \mathrm{~m}$ asl). The soil was of the LVE type, sandy texture (16\% clay). Sowing, seedling production and planting of the experimental plots were carried out in February 2013, in a randomized complete block design, with three replications. Each plot consisted of 20 seedlings spaced $0.50 \mathrm{~m}$ apart, distributed in two $5-\mathrm{m}$ long furrows spaced $1.40 \mathrm{~m}$ apart.

The mechanical cutting of the cane crop occurred in December 2013. The experiment was evaluated after 12 months (December 2014), in the ratoon cane cycle, which is a rather unfavorable harvest season due to the increased drought stress, causing losses in the agricultural and industrial quality of the crop.

The following traits were evaluated in the families at the plot level: a mean number of stalks per seedling (NSt), calculated as:

$$
N S t=\frac{\text { number of stalks per plot }}{n}
$$

(Equation 1)

where $n$ is the number of surviving clumps per plot; weight of one stalk (W1St), estimated by weighing 20 stalks per plot; sampling of 20 random stalks per plot for technical analysis in the laboratory, where the percentage values of soluble solids content (BRIX), apparent sucrose, also known as pol\%cane (PC), and fiber (FIB) were determined.

The stalk weight (WSt) was calculated by weighing all plants per plot (total plot weight) and counting the number of stalks per plot, according to the expression:

$$
W S t=\frac{\text { total plot weight }}{\text { number of stalks per plot }} \quad \text { (Equation 2) }
$$

The yield in tons of cane per hectare (TCH) was obtained by the expression:

$$
T C H=\frac{N s t \times W 1 S t \times 10}{A P}
$$

where $A P$ is the area occupied per clump per plot in $\mathrm{m}^{2}(\mathrm{AP}=1.12)$, and 10 is the constant used to convert plot weight to $t / h a$. Due to the dead plants in some plots of the experiment, there was a concern to calculate TCH by the above expressions, without penalizing the families with lower number of surviving plants, since a major part of the deaths was caused by sedimentation in the planting furrow due to heavy rainfall in the beginning of the experiment.

Based on TCH and PC the trait tons of sucrose per hectare (TSH) was estimated:

$$
T S H=\frac{T C H \times P C}{100}
$$

(Equation 4)

To calculate tons of fiber per hectare (TFH), the traits TCH were used in the expression:

$$
T F H=\frac{T C H \times F I B}{100}
$$

Genetics and Molecular Research 16 (3): gmr16039773 
For the analyses, the mean plot data were used, and the SELEGEN program (Resende, 2016), model 20 (random blocks, a test of independent clones, one plant per plot, or plot mean) was used, indicated in the form of a matrix by:

$$
y=X r+Z g+e
$$

(Equation 6)

where: $y$ is the known, observed data vector; $r$ is the vector of effects of unknown replications (assumed as fixed); $g$ is the vector of unknown genotypic effects (assumed as random); $e$ is the vector of (random) errors; and $X$ and $Z$ are incidence matrices for the said effects, where $g \sim N(0, G), e \sim N(0, R), E(y)=X r$, and $V(y)=Z G Z^{\prime}+R . G$ is the matrix of variances and covariances of the genetic effects and $R$ the matrix of variances and covariances of errors. For this model, the mixed model equations are as follows (Resende, 2002):

$$
\left(\begin{array}{ccc}
X^{\prime} R^{-1} X & X^{\prime} R^{-1} & Z \\
Z^{\prime} R^{-1} X & Z^{\prime} R^{-1}+G^{-1}
\end{array}\right)\left(\begin{array}{l}
\hat{r} \\
\hat{g}
\end{array}\right)=\left(\begin{array}{c}
X^{\prime} R^{-1} y \\
Z^{\prime} R^{-1} y
\end{array}\right)
$$

\section{RESULTS AND DISCUSSION}

According to deviance analysis, the genotypic variance was significant for all traits, indicating the existence of genetic variability that can be explored by family selection (Table 2 ).

Table 2. General mean, genotypic variance $(\mathrm{Vg})$, coefficient of genetic variation $(\mathrm{CVg})$, coefficient of environmental variation (CVe), mean broad-sense heritability $\left(\mathrm{h}^{2}\right)$, and accuracy $(\mathrm{Ac})$ of yield and processing traits evaluated in 30 sugar- and energy cane families in Paranavaí, Paraná, Brazil.

\begin{tabular}{l|c|c|c|c|c|c}
\hline Traits & General mean & Vg & CVg (\%) & CVe (\%) & $\mathrm{h}^{2}$ & Ac \\
\hline BRIX & 19.85 & $1.31^{* *}$ & 5.77 & 6.41 & 0.71 & 0.84 \\
\hline PC & 12.96 & $2.46^{* *}$ & 12.10 & 9.00 & 0.84 & 0.92 \\
\hline FIB & 15.71 & $0.78^{* *}$ & 5.62 & 6.24 & 0.71 & 0.84 \\
\hline TCH & 87.71 & $339.94^{* *}$ & 21.02 & 32.59 & 0.56 & 0.75 \\
\hline TSH & 11.36 & $5.24^{*}$ & 20.15 & 36.79 & 0.47 & 0.69 \\
\hline TFH & 13.67 & $9.02^{* *}$ & 21.97 & 30.59 & 0.61 & 0.78 \\
\hline
\end{tabular}

BRIX $=$ soluble solids content; $\mathrm{PC}=$ apparent sucrose content; $\mathrm{FIB}=$ fiber content; $\mathrm{TCH}=$ tons of cane per hectare; $\mathrm{TSH}=$ tons of sucrose per hectare; TFH $=$ tons of fiber per hectare. *** Significant at 5 and $1 \%$, respectively, according to deviance analysis.

The coefficients of genetic variation $(\mathrm{CVg})$, which expressed the amount of genetic variation as a percentage of the general mean, were moderate for the processing traits: FIB and BRIX (5.62 and 5.77\%, respectively); and high for PC (12.10\%). For the yield-related traits TSH, $\mathrm{TCH}$, and TFH, the values were high $(20.15,21.02$, and $21.97 \%$, respectively). In the studies of sugarcane families of Moraes et al. (2010), the results of $\mathrm{CVg}$ for TCH and TSH were very similar (19.51 and 19.56\%), and lower for FIB, BRIX, and PC (1.46 to 5.08\%). Balsalobre et al. (2016) reported very close values for BRIX, PC, and FIB, and lower values for the traits TCH and TSH.

The coefficient of environmental variation $(\mathrm{CVe})$ is the parameter that indicates the level of experimental precision. The $\mathrm{CVe}$ for the processing traits were considered low, ranging from $6.24 \%$ for FIB to $9 \%$ for PC. However, the coefficients of variation of TCH, TSH, and TFH were higher $(32.59,36.78$, and $30.60 \%$, respectively) (Table 2). In studies with sugarcane families, Jackson et al. (1995) and Moraes et al. (2010) found similar values

Genetics and Molecular Research 16 (3): gmr16039773 
for these traits. In studies of energy cane families, Silveira et al. (2016) found very similar values of $\mathrm{CVe}$ for the traits PC, FIB, TCH, TSH, and TFH to those obtained in this study. The high value of $\mathrm{CVe}$ for TCH, according to the classification proposed by Gomes (1990), can be attributed in part to the data heterogeneity and the strong environmental influence on this complex trait. The same is true for TSH and TFH, which are dependent and highly correlated with TCH. In general, the experimental precision can be considered adequate considering the coefficient of environmental variation and the significance of genetic variability among the families evaluated (Table 2).

According to the classification proposed by Resende (2002), the estimated heritability $\left(h^{2}\right)$ values were considered high for all traits (above 0.50 ) except for TSH (very similar result, with 0.47). This indicated the influence of the genetic component of the expression of the respective traits, and consequently the possibility of success with selection (Table 2). These results are consistent with the study of Kang et al. (1983) for BRIX and TCH; of Melo et al. (2006), for PC, BRIX, FIB, and TCH; and in the stufy of Silva et al. (2011), for the traits BRIX, PC, TCH, and TSH. Silveira et al. (2016) found very close heritability values for PC, $\mathrm{FIB}$, and $\mathrm{TCH}$, and lower values for TSH and TFH in evaluations of sugarcane families.

Accuracy (Ac) indicates the precision of inferences about the genotypic means because, according to Resende (2002), this property informs about the correct ranking of families for selection purposes, and also about the efficacy of inference about the genotypic value, i.e., the correlation between predicted and true genotypic values. According to Resende and Duarte (2007), the results are moderate $(0.69$ or $69 \%)$ for TSH and very high $(0.92$ or $92 \%$ ) for PC. The traits of interest for selection and classification of families were intermediate values $(\mathrm{TCH}=0.75, \mathrm{TSH}=0.69 ; \mathrm{TFH}=0.78)$, indicating good precision and, therefore, the reliability of the estimated genetic values, ensuring security in the selection. According to Resende (2002), values of this order are adequate in the initial phase of breeding programs.

The crosses RB867515 x RB965518, MEX68-200 x F150, CoS245 x RB813804, MEX68-200 x RB93509, RB867515 x RB996961, and RB855156 x RB987935 had the highest values for BRIX and PC. This higher genotype means for soluble solids, and apparent sucrose contents were because these families resulted from crosses between elite clones and commercial cultivars of sugarcane (SC). An exception was the INT families of crosses involving the parents MEX68-200, CoS245, and F150, all of the third generation of $S$. spontaneum, i.e., very close to Saccharum spp, with higher sugar contents (Table 3).

For FIB, the crosses with highest values were RB01640 x IN84-58, RB92579 x IM76-229, F150 x IN84-88, IM76-228 x RB867515, RB92579 x IM76-228, and SP81-3250 x US85-1008, which are energy cane (EC) families of crosses with sugarcane hybrids and $S$. spontaneum (IN84-58 and IN84-88), S. robustum (IM76-229 and IM76-228), and the first generation of S. spontaneum (US85-1008) (Table 3).

The relationship between PC and FIB (Figure 1) shows a negative correlation between sugarcane (SC) and energy cane (EC) families, where crosses with sugarcane hybrids were concentrated in the first quadrant, showing a higher sucrose content at the expense of fiber content.

The S. spontaneum and S. robustum families were concentrated in the fourth quadrant, with higher fiber at the expense of sugar contents. This pattern demonstrates the importance of these species for fiber increment in breeding programs for energy cane. The exploitation of these parents has generated plants with higher fiber content than of other species of the genus Saccharum (Ming et al., 2006; Tew and Cobill, 2008). This has been the strategy to increase biomass in breeding programs in several countries, e.g., in Puerto Rico (Alexander, 1985), the

Genetics and Molecular Research 16 (3): gmr16039773 
United States (Giamalva et al., 1985; Eggleston et al., 2007), Barbados (Rao et al., 2007), and Mauritius (Ramdoyal and Badaloo, 2007). In Brazil, studies on energy cane are more recent (Matsuoka et al., 2014; Carvalho-Netto et al., 2014; Silveira et al., 2015a,b, 2016; Ramos et al., 2017; de Azeredo et al., 2017).

Table 3. Family parents, classification of crosses (type), genotypic means, and their respective ranking for the yield-related traits evaluated in 30 sugar- and energy cane families in Paranavaí, Paraná, Brazil.

\begin{tabular}{|c|c|c|c|c|c|c|c|c|c|c|c|c|c|c|}
\hline \multicolumn{3}{|c|}{ Families* } & \multicolumn{12}{|c|}{ Traits** } \\
\hline Mother & Father & Type & $\mathrm{BR}$ & & & & & & $\mathrm{TC}$ & & & & & \\
\hline RB855156(1) & RB987935(1) & $\mathrm{SC}$ & 20.98 & $6^{\circ}$ & 14.75 & $2^{\circ}$ & 15.90 & $14^{\circ}$ & 98.20 & $8^{\circ}$ & 13.65 & $2^{\circ}$ & 15.73 & $5^{\circ}$ \\
\hline RB867515(1) & RB965518(1) & $\mathrm{SC}$ & 21.26 & $1^{\circ}$ & 14.67 & $4^{\circ}$ & 14.78 & $27^{\circ}$ & 78.71 & $23^{\circ}$ & 11.06 & $17^{\circ}$ & 11.61 & $24^{\circ}$ \\
\hline RB867515(1) & RB996961 $^{(1)}$ & $\mathrm{SC}$ & 21.06 & $5^{\circ}$ & 14.72 & $3^{\circ}$ & 15.89 & $15^{\circ}$ & 81.43 & $21^{\circ}$ & 11.47 & $15^{\circ}$ & 12.64 & $20^{\circ}$ \\
\hline RB966928 (1) & TUC77-42 ${ }^{(1)}$ & $\mathrm{SC}$ & 20.64 & $9^{\circ}$ & 13.81 & $12^{\circ}$ & 16.10 & $10^{\circ}$ & 64.29 & $29^{\circ}$ & 8.97 & $28^{\circ}$ & 9.87 & $29^{\circ}$ \\
\hline SP80-3280(1) & RB867515(1) & $\mathrm{SC}$ & 20.70 & $8^{\circ}$ & 13.97 & $10^{\circ}$ & 15.24 & $19^{\circ}$ & 94.02 & $11^{\circ}$ & 12.90 & $7^{\circ}$ & 14.48 & $14^{\circ}$ \\
\hline Co62175 ${ }^{(1)}$ & $28 \mathrm{NG} 289^{(3)}$ & $\mathrm{EC}$ & 17.86 & $30^{\circ}$ & 10.64 & $28^{\circ}$ & 16.27 & $8^{\circ}$ & 92.01 & $15^{\circ}$ & 10.53 & $21^{\circ}$ & 14.82 & $12^{\circ}$ \\
\hline IAC87-3396 ${ }^{(1)}$ & US85-1008(4) & $\mathrm{EC}$ & 19.29 & $20^{\circ}$ & 12.38 & $19^{\circ}$ & 16.30 & $7^{\circ}$ & 92.42 & $14^{\circ}$ & 11.61 & $13^{\circ}$ & 15.00 & $8^{\circ}$ \\
\hline IM76-228 $8^{(3)}$ & RB867515 $^{(1)}$ & $\mathrm{EC}$ & 19.04 & $22^{\circ}$ & 10.64 & $28^{\circ}$ & 16.80 & $4^{\circ}$ & 91.27 & $16^{\circ}$ & 10.51 & $22^{\circ}$ & 15.22 & $7^{\circ}$ \\
\hline RB01640 (1) & IN84-58 (2) & $\mathrm{EC}$ & 19.00 & $23^{\circ}$ & 11.33 & $26^{\circ}$ & 17.07 & $1^{\circ}$ & 73.65 & $25^{\circ}$ & 9.24 & $27^{\circ}$ & 12.13 & $22^{\circ}$ \\
\hline RB036066 ${ }^{(1)}$ & $?^{(2)}$ & $\mathrm{EC}$ & 18.89 & $26^{\circ}$ & 11.37 & $25^{\circ}$ & 15.87 & $16^{\circ}$ & 115.13 & $1^{\circ}$ & 13.21 & $5^{\circ}$ & 18.62 & $1^{\circ}$ \\
\hline RB04813(1) & US85-1008 ${ }^{(4)}$ & $\mathrm{EC}$ & 18.92 & $24^{\circ}$ & 11.65 & $24^{\circ}$ & 15.96 & $12^{\circ}$ & 81.56 & $20^{\circ}$ & 10.16 & $25^{\circ}$ & 12.83 & $19^{\circ}$ \\
\hline RB83102(1) & IM76-229(3) & $\mathrm{EC}$ & 19.57 & $18^{\circ}$ & 12.67 & $17^{\circ}$ & 16.00 & $11^{\circ}$ & 106.53 & $2^{\circ}$ & 13.34 & $3^{\circ}$ & 17.26 & $2^{\circ}$ \\
\hline RB867515(1) & B70710 $0^{(4)}$ & $\mathrm{EC}$ & 19.16 & $21^{\circ}$ & 11.76 & $23^{\circ}$ & 14.81 & $26^{\circ}$ & 99.04 & $7^{\circ}$ & 12.21 & $11^{\circ}$ & 14.75 & $13^{\circ}$ \\
\hline RB92579(1) & IM76-228 & $\mathrm{EC}$ & 18.36 & $29^{\circ}$ & 10.60 & $30^{\circ}$ & 16.44 & $5^{\circ}$ & 99.39 & $5^{\circ}$ & 11.20 & $16^{\circ}$ & 16.47 & $3^{\circ}$ \\
\hline RB92579 & IM76-229 & $\mathrm{EC}$ & 19.64 & $17^{\circ}$ & 12.43 & $18^{\circ}$ & 16.93 & $2^{\circ}$ & 86.00 & $18^{\circ}$ & 11.00 & $18^{\circ}$ & 14.25 & $16^{\circ}$ \\
\hline RB93509 $9^{(1)}$ & Co285 & $\mathrm{EC}$ & 19.94 & $14^{\circ}$ & 13.58 & $15^{\circ}$ & 15.18 & $20^{\circ}$ & 94.06 & $10^{\circ}$ & 12.34 & $10^{\circ}$ & 14.37 & $15^{\circ}$ \\
\hline SP81-3250 $0^{(1)}$ & US85-1008 ${ }^{(4)}$ & $\mathrm{EC}$ & 19.33 & $19^{\circ}$ & 11.97 & $21^{\circ}$ & 16.41 & $6^{\circ}$ & 68.60 & $28^{\circ}$ & 8.93 & $29^{\circ}$ & 10.75 & $27^{\circ}$ \\
\hline Co421 $1^{(5)}$ & POJ2878 ${ }^{(6)}$ & INT & 18.76 & $28^{\circ}$ & 11.85 & $22^{\circ}$ & 16.18 & $9^{\circ}$ & 54.83 & $30^{\circ}$ & 7.55 & $30^{\circ}$ & 8.17 & $30^{\circ}$ \\
\hline $\operatorname{Co} 421^{(5)}$ & RB93509 $9^{(1)}$ & INT & 20.28 & $12^{\circ}$ & 14.03 & $9^{\circ}$ & 14.72 & $29^{\circ}$ & 93.10 & $13^{\circ}$ & 12.50 & $9^{\circ}$ & 13.88 & $18^{\circ}$ \\
\hline CoS245(6) & RB813804(1) & INT & 21.15 & $3^{\circ}$ & 14.56 & $6^{\circ}$ & 15.09 & $22^{\circ}$ & 73.47 & $26^{\circ}$ & 10.35 & $24^{\circ}$ & 10.90 & $26^{\circ}$ \\
\hline Co617(5) & POJ2878(6) & INT & 18.92 & $24^{\circ}$ & 12.02 & $20^{\circ}$ & 15.96 & $12^{\circ}$ & 97.56 & $9^{\circ}$ & 11.98 & $12^{\circ}$ & 15.48 & $6^{\circ}$ \\
\hline $\mathrm{F} 150^{(6)}$ & IN84- $88^{(2)}$ & INT & 18.82 & $27^{\circ}$ & 10.85 & $27^{\circ}$ & 16.84 & $3^{\circ}$ & 89.04 & $17^{\circ}$ & 10.41 & $23^{\circ}$ & 14.91 & $10^{\circ}$ \\
\hline F160 $0^{(6)}$ & MEX68-200 ${ }^{(6)}$ & INT & 20.48 & $11^{\circ}$ & 13.87 & $11^{\circ}$ & 15.09 & $22^{\circ}$ & 105.09 & $3^{\circ}$ & 13.78 & $1^{\circ}$ & 15.83 & $4^{\circ}$ \\
\hline MEX68-200 ${ }^{(6)}$ & $\mathrm{F} 150^{(6)}$ & INT & 21.19 & $2^{\circ}$ & 14.64 & $5^{\circ}$ & 14.94 & $25^{\circ}$ & 82.35 & $19^{\circ}$ & 11.51 & $14^{\circ}$ & 12.28 & $21^{\circ}$ \\
\hline MEX68-200 ${ }^{(6)}$ & RB040823 $^{(1)}$ & INT & 19.83 & $15^{\circ}$ & 13.61 & $14^{\circ}$ & 14.50 & $30^{\circ}$ & 100.98 & $4^{\circ}$ & 13.23 & $4^{\circ}$ & 14.84 & $11^{\circ}$ \\
\hline MEX68-200 ${ }^{(6)}$ & RB93509(1) & INT & 21.14 & $4^{\circ}$ & 14.87 & $1^{\circ}$ & 15.00 & $24^{\circ}$ & 75.37 & $24^{\circ}$ & 10.74 & $20^{\circ}$ & 11.18 & $25^{\circ}$ \\
\hline $\mathrm{RB} 01623^{(1)}$ & MEX68-200 ${ }^{(6)}$ & INT & 19.82 & $16^{\circ}$ & 13.22 & $16^{\circ}$ & 15.59 & $17^{\circ}$ & 71.24 & $27^{\circ}$ & 9.66 & $26^{\circ}$ & 10.71 & $28^{\circ}$ \\
\hline RB93509 $9^{(1)}$ & \begin{tabular}{|l|} 
Co $421^{(5)}$ \\
\end{tabular} & INT & 20.59 & $10^{\circ}$ & 14.32 & $8^{\circ}$ & 14.77 & $28^{\circ}$ & 94.02 & $11^{\circ}$ & 12.81 & $8^{\circ}$ & 13.99 & $17^{\circ}$ \\
\hline RB93509 $^{(1)}$ & MEX68-200 ${ }^{(6)}$ & INT & 20.05 & $13^{\circ}$ & 13.78 & $13^{\circ}$ & 15.10 & $21^{\circ}$ & 99.06 & $6^{\circ}$ & 13.10 & $6^{\circ}$ & 14.97 & $9^{\circ}$ \\
\hline US74-103 ${ }^{(5)}$ & RB92579 $9^{(1)}$ & INT & 20.75 & $7^{\circ}$ & 14.36 & $7^{\circ}$ & 15.46 & $18^{\circ}$ & 78.95 & $22^{\circ}$ & 10.95 & $19^{\circ}$ & 12.10 & $23^{\circ}$ \\
\hline
\end{tabular}

*Types of families defined by the genealogical data: SC: sugarcane family; EC: energy cane family; INT: (2nd and 3rd generations of $S$. spontaneum). **BRIX = soluble solids content; PC = apparent sucrose content; FIB = fiber content; $\mathrm{TCH}=$ tons of cane per hectare; $\mathrm{TSH}=$ tons of sucrose per hectare; $\mathrm{TFH}=$ tons of fiber per hectare. ${ }^{1}$ Sugarcane hybrid (Saccharum spp), ${ }^{2}$ Saccharum spontaneum, ${ }^{3}$ Saccharum robustum, ${ }^{4} 1$ st generation of $S$. spontaneum, ${ }^{5} 2$ nd generation of $S$. spontaneum, ${ }^{6} 3 \mathrm{rd}$ generation of $S$. spontaneum, 'unknown parent of multiparental cross.

In the INT families, a different behavior was observed for the traits PC and FIB, with higher sucrose contents in some and higher fiber contents in others. The crosses Co617 x POJ2878 and Co421 x POJ2878, both parents of second and third generations of S. spontaneum, respectively, originated families with a stronger trend of fiber accumulation and a considerable decrease in sucrose content. For the crosses F160 x MEX68-200 and MEX68-200 x F150, both third-generation accessions of $S$. spontaneum, an opposite trend was observed, with higher sucrose accumulation and lower fiber contents (Figure 1).

For TCH, the best-performing families were RB036066 x ? (SC, $115.13 \mathrm{t} / \mathrm{ha}$ ); RB83102 x IM76-229 (EC, 106.53 t/ha); F160 x MEX68-200 (INT, 105.09 t/ha); MEX68200 x RB040823 (INT, 100.98 t/ha); RB92579 x IM76-228 (EC, 99.39 t/ha); and RB93509 x MEX68-200 (INT, 99.06 t/ha) (Table 3). It is worth remembering that the parents RB040823, RB036066, RB93509, RB92579, and RB83102 are current sugarcane cultivars (except the parents of cross F160 x MEX68-200), which contributed to increase TCH in these families.

Genetics and Molecular Research 16 (3): gmr16039773 


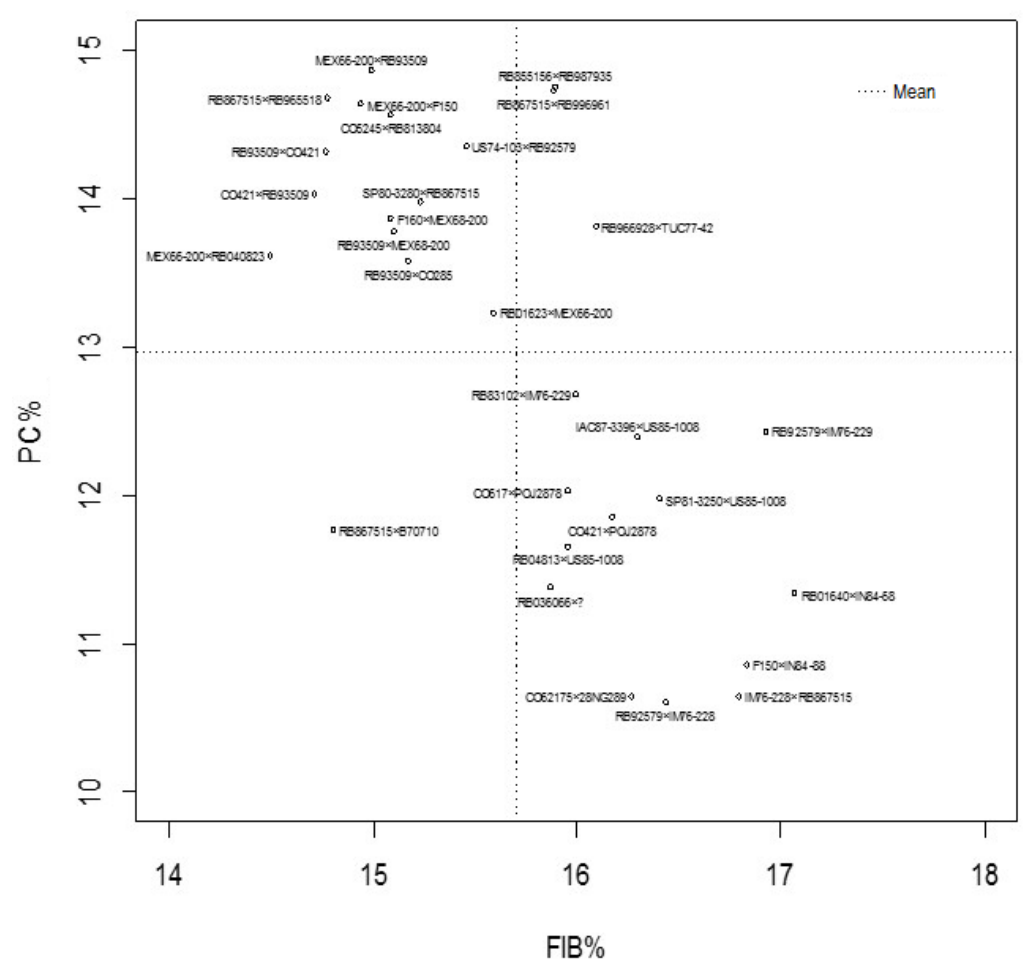

Figure 1. Scatter plot illustrating the correlation between the means of apparent sucrose percentage [PC (\%)] and fiber content [FIB (\%)] in an evaluation of 30 sugar- and energy cane families.

For TSH, the results are shown more clearly in the isoquant-type graph (Figure 2). The following families appear above the first isoline: F160 x MEX68-200 (INT, $13.78 \mathrm{t} / \mathrm{ha}$ ), and RB855156 x RB987935 (SC, 13.65 t/ha). The cross F160 x MEX68-200, with parents of the third $S$. spontaneum generation, had a particularly interesting performance, with a considerable contribution to sucrose and stalk yield increase, generating progenies with higher TSH; the other crosses with the same parents did not have the same behavior pattern. The crosses between the first and second isolines were RB83102 x IM76-229 (EC), MEX68-200 x RB040823 (INT), RB036066 x ? (EC), RB93509 x Co421 (INT), Co421 x RB93509 (INT), and RB93509 x Co285 (INT), in descending order of TSH values (EC), RB93509 x MEX68200 (INT), and SP80-3280 x RB867515 (SC) (Table 3). The energy cane (EC) families had a high performance for TSH, improved by $\mathrm{TCH}$, whereas $\mathrm{PC}$ was far below the mean; the other families had above-mean TCH and PC values.

The performance of the families for TFH is also shown in isoquant diagrams (Figure 3). Cross RB036066 x ? (EC), of a half-sib with $S$. spontaneum accessions, appears above the first isoline. This is the most productive family $(\mathrm{TFH}=18.62)$, with an average performance for FIB (15.87\%), while the high fiber yield was averaged by TCH (115.13 t/ha). Between the first and second isoline are the crosses RB83102 x IM76-229 (EC) and RB92579 x IM76-228 (EC), both families with good performance in TCH and high FIB content; the parents of these families are high-yielding sugarcane hybrids and S. robustum accessions.

Genetics and Molecular Research 16 (3): gmr16039773 
Genetic parameters in sugar and energy cane families

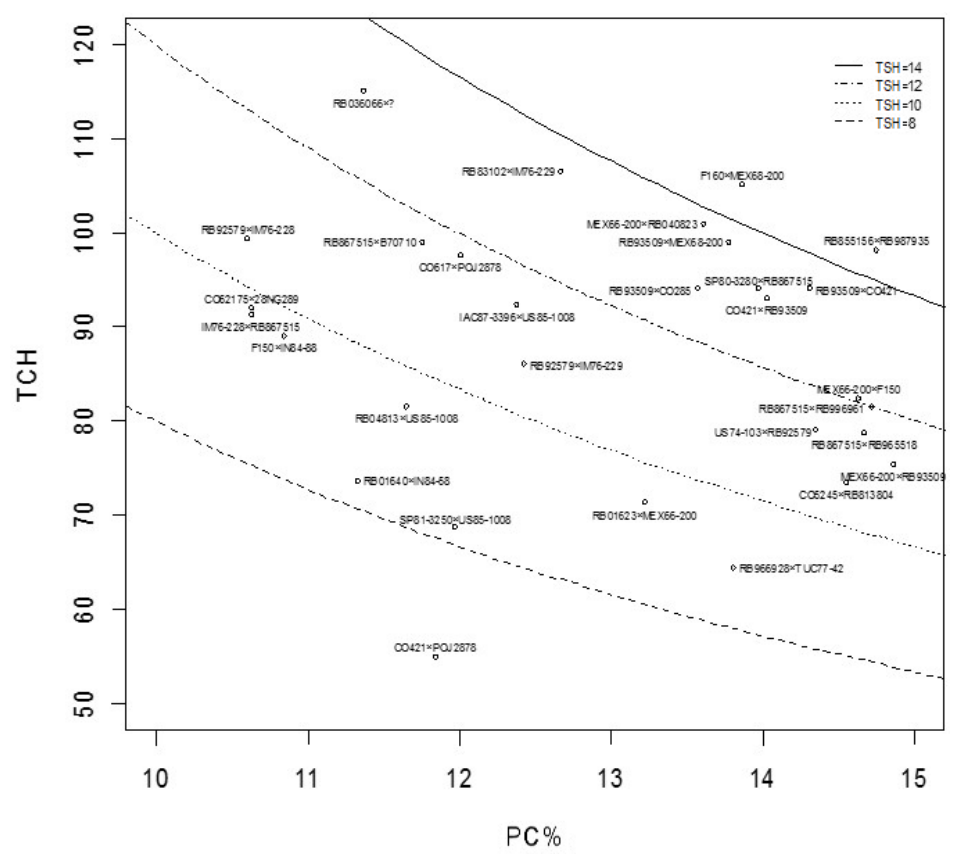

Figure 2. Isoquant diagram of tons of sucrose per hectare (TSH) in the evaluation of 30 sugar- and energy cane families in Paranavaí - PR.

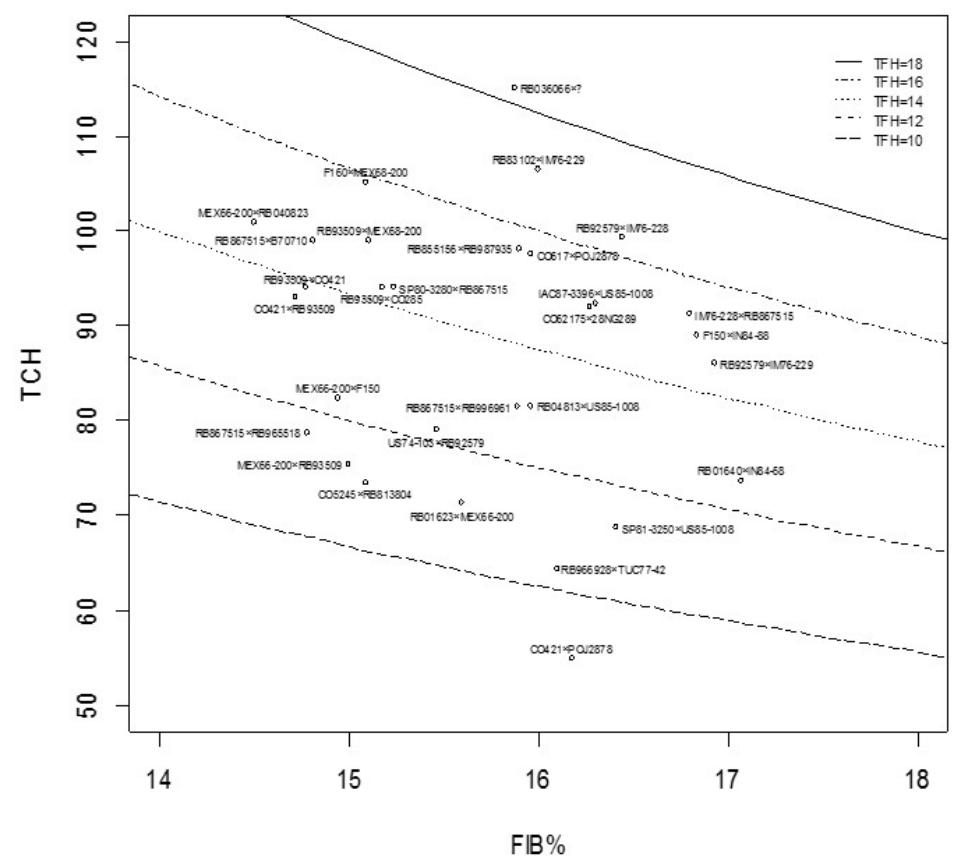

Figure 3. Isoquant diagram of tons of fiber per hectare (TFH) in the evaluation of 30 sugar- and energy cane families in Paranavaí - PR.

Genetics and Molecular Research 16 (3): gmr16039773 


\section{CONCLUSIONS}

The families F160 x MEX68-200 and RB855156 x RB987935 had the highest sucrose yields per hectare. The family RB036066 x ? had the highest fiber yield per hectare since the cane yield (TCH) was the highest and the fiber content intermediate. The excellent performance of TFH was also observed in families derived from crosses of sugarcane cultivars with $S$. robustum accessions.

Heritability and accuracy were high for all evaluated traits, reflecting a considerable presence of the genetic component in trait expression and evidencing precision in the prediction of the genotypic means, indicating efficiency in the selection of sugar- and energy cane families for processing and yield-related traits.

\section{Conflicts of interest}

The authors declare no conflict of interest.

\section{ACKNOWLEDGMENTS}

The authors are indebted to the Brazilian Federal Agency for Support and Evaluation of Graduate Education (CAPES), the Brazilian Council for Scientific and Technological Development (CNPq), the Foundation of the Federal University of Paraná (FUNPAR), and the Sugarcane Breeding Program of the Federal University of Paraná/Inter-University Network for the Development of Sugarcane Industry PMGCA/UFPR/RIDESA.

\section{REFERENCES}

Alexander AG (1985). The Energy Cane Alternative. Elsevier, Amsterdam.

de Azeredo AAC, Bhering LL, Brasileiro BP, Cruz CD, et al. (2017). Comparison between different selection indices in energy cane breeding. Genet. Mol. Res. 16: 1-12. https://doi.org/10.4238/gmr16019535

Balsalobre TWA, Mancini MC, Pereira GS, Anoni CO, et al. (2016). Mixed modeling of yield components and brown rust resistance in sugarcane families. Agron. J. 108: 1824-1837. https://doi.org/10.2134/agronj2015.0430

Barbosa MHP, Resende MDV, Bressiani JA, Silveira RCI, et al. (2005). Selection of sugarcane families and parents by REML/BLUP. Crop Breed. Appl. Biotechnol. 5: 443-450. https://doi.org/10.12702/1984-7033.v05n04a10

Barbosa MHP, Resende MDV, Dias LAS, et al. (2012). Genetic improvement of sugarcane for bioenergy: the Brazilian experience in network research with RIDESA. Crop Breed. Appl. Biotechnol. 12: 87-98. https://doi.org/10.1590/ $\underline{\text { S1984-70332012000500010 }}$

Brasileiro BP, Mendes TOP, Peternelli LA, et al. (2016). Simulated Individual Best Linear Unbiased Prediction versus Mass Selection in Sugarcane Families. Crop Sci. 56: 570-575. https://doi.org/10.2135/cropsci2015.03.0199

Carvalho-Netto OV, Bressian IJA, Soriano HL, et al. (2014). The potential of the energy cane as the main biomass crop for the cellulosic industry. Chem. Biol. Technol. Agric 1: 1-20. https://doi.org/10.1186/s40538-014-0020-2

Dal-Bianco M, Carneiro MS, Hotta CT, Chapola RG, et al. (2012). Sugarcane improvement: how far can we go? Curr. Opin. Biotechnol. 23: 265-270. https://doi.org/10.1016/j.copbio.2011.09.002

Eggleston G, Salassi M, Richard E, et al. (2007). Sustainability of the sugar industry: Future value addition from sugarcane. Int. Sugar J. 109: 415-432.

Giamalva M, Clark S and Stein J (1985). Conventional vs high fiber sugarcane. J. Am. Soc. Sugar Tech 4: 106-109.

Gomes FP (1990). Curso de estatística experimental. 13. ed. Ed. da USP, Piracicaba.

Jackson PA, Mcrae TA and Hogarth DM (1995). Selection of sugarcane families across variable environments. In. Sources of variation and optimal selection index. Field Crops Res. 43: 109-118. https://doi.org/10.1016/0378-4290(95)00039-S

Kang MS, Miller JD and Tai PYP (1983). Genetic and phenotypic path analysis and heritability in sugarcane. Crop Sci. 23: 643-647. https://doi.org/10.2135/cropsci1983.0011183X002300040010x

Genetics and Molecular Research 16 (3): gmr16039773 
Kimbeng CA and Cox MC (2003). Early generation selection of sugarcane families and clones in Australia: a review. $J$. Am. Soc. Sugar Tech 23: 20-39.

Matsuoka S, Kennedy AJ, Santos EGD, et al. (2014). Energy Cane: Its Concept, Development, Characteristics, and Prospects. Adv. Bot. 1-13.

Melo LJOT, Oliveira FJ, Bastos GQ, Anunciação Filho CJ, et al. (2006). Interação genótipo x ciclos de colheita de cana-de-açúcar da Zona da Mata Norte de Pernambuco. Bragantia 65: 197-205. https://doi.org/10.1590/S000687052006000200002

Ming R, Moore PH, D’Hont A, Glaszmann JC, et al. (2006). Sugarcane Improvement through Breeding and Biotechnology. In: Plant breeding reviews (Janick J, ed.). John Wiley \& Sons, New York.

Moraes MF, Bastos GQ, Filho CJA, et al. (2010). Avaliação agroindustrial e parâmetros genético de progênies de cana-deaçúcar em fase inicial na zona canavieira do litoral norte de Pernambuco. Cienc. Agrotec. 34: 1086-1092. https://doi. org/10.1590/S1413-70542010000500002

Oliveira RA, Daros E, Resende MDV, et al. (2011). Procedimento Blupis e seleção massal em cana-de-açúcar. Bragantia 70: 796-800. https://doi.org/10.1590/S0006-87052011000400010

Ramdoyal K and Badaloo GH (2007). An evaluation of interspecific families of different nobilised groups in contrasting environments for breeding novel sugarcane clones for biomass. In: Proceedings of the International Society of Sugar Cane Technologists Conference, 26: 632-645.

Ramos RS, Brasileiro BP, Silveira LCI, et al. (2017). Selection of parents, families and clones to obtain energy cane. Agron. J. 109: 1-7. https://doi.org/10.2134/agronj2016.09.0489

Rao PS, Davis H and Simpson C (2007). New sugarcane cultivars and year round sugar and ethanol production with bagasse-based cogeneration in Barbados and Guiana. Proceedings of the 2007 Congress, Int. Soc. Sugar Cane Technol. 26: 1169-1176.

Resende MDV (2002). Genética biométrica e estatística no melhoramento de plantas perenes. Embrapa Informação Tecnológica, Brasília.

Resende MDV (2016). Software Selegen-REML/BLUP: a useful tool for plant breeding. Crop Breed. Appl. Biotechnol. 16: 330-339. https://doi.org/10.1590/1984-70332016v16n4a49

Resende MDV and Barbosa MHP (2006). Selection via simulated Blup base on family genotypic effects in sugarcane. Pesqui. Agropecu. Bras. 41: 421-429. https://doi.org/10.1590/S0100-204X2006000300008

Resende MDV and Duarte JB (2007). Precisão e controle de qualidade em experimentos de avaliação de cultivares. Pesqui. Agropecu. Trop. 37: 182-194.

Silva GC, Oliveira FJ, and Anunciação Filho CJ, Simões Neto DE, et al. (2011). Divergência genética entre genótipos de cana-de-açúcar. Ver. Bras. Ciênc. Agrá. 6: 52-58.

Silveira LCI, Brasileiro BP, Kist V, et al. (2015a). Genetic diversity and coefficient of kinship among potential genitors for obtaining cultivars of energy cane. Rev. Ciên. Agronôm. 46: 358-368.

Silveira LCI, Brasileiro BP, Kist V, et al. (2015b). Selection strategy in families of energy cane based on biomass production and quality traits. Euphytica 204: 443-455. https://doi.org/10.1007/s10681-015-1364-9

Silveira LCI, Brasileiro BP, Kist V, et al. (2016). Selection in energy cane families. Crop Breed. Appl. Biotechnol. 16: 298306. https://doi.org/10.1590/1984-70332016v16n4a45

Simmonds NW (1996). Family selection in plant breeding. Euphytica 90: 201-208. https://doi.org/10.1007/BF00023859

Stringer JK, Cox MC, Atkin FC, et al. (2011). Family selection improves the efficiency and effectiveness of selecting original seedlings and parents. Sugar Tech 13: 36-41. https://doi.org/10.1007/s12355-011-0073-5

Tew TL and Cobill RM (2008). Genetic Improvement of Sugarcane (Saccharum spp.) as an Energy Crop. In: Genetic Improvement of Bioenergy Crops (Vermerris W, ed.). Springer, New York.

Vichi FM and Mansor MTC (2009). Energia, meio ambiente e economia: o Brasil no contexto mundial. Quim. Nova 32: 757-767. https://doi.org/10.1590/S0100-40422009000300019

Wang L, Jackson PA, Lu X, et al. (2008). Evaluation of sugarcane x Saccharum spontaneum progeny for biomass composition and yield components. Crop Sci. 48: 951-996. https://doi.org/10.2135/cropsci2007.10.0555

Zeni Neto H, Daros E, Bespalhok Filho JC, et al. (2013). Selection of families and parents of sugarcane (Saccharum spp.) through mixed models by joint analysis of two harvests. Euphytica 193: 391-408. https://doi.org/10.1007/s10681$\underline{013-0947-6}$ 